This is an electronic reprint of the original article. This reprint may differ from the original in pagination and typographic detail.

\author{
Author(s): Kraemer, William J.; Hooper, David R.; Kupchak, Brian R.; Saenz, Catherine; Brown, Lee \\ E.; Vingren, Jakob L.; Luk, Hui Ying; DuPont, William H.; Szivak, Tunde K.; Flanagan, \\ Shawn D.; Caldwell, Lydia K.; Eklund, Daniela; Lee, Elaine C.; Häkkinen, Keijo; Volek, \\ Jeff S.; Fleck, Steven J.; Maresh, Carl M.
}

Title: The Effects of a Roundtrip Trans-American Jet Travel on Physiological Stress, Neuromuscular Performance and Recovery

Year: $\quad 2016$

Version:

Please cite the original version:

Kraemer, W. J., Hooper, D. R., Kupchak, B. R., Saenz, C., Brown, L. E., Vingren, J. L., Luk, H. Y., DuPont, W. H., Szivak, T. K., Flanagan, S. D., Caldwell, L. K., Eklund, D., Lee, E. C., Häkkinen, K., Volek, J. S., Fleck, S. J., \& Maresh, C. M. (2016). The Effects of a Roundtrip Trans-American Jet Travel on Physiological Stress, Neuromuscular Performance and Recovery. Journal of Applied Physiology, 121(2), 438-448. https://doi.org/10.1152/japplphysiol.00429.2016

All material supplied via JYX is protected by copyright and other intellectual property rights, and duplication or sale of all or part of any of the repository collections is not permitted, except that material may be duplicated by you for your research use or educational purposes in electronic or print form. You must obtain permission for any other use. Electronic or print copies may not be offered, whether for sale or otherwise to anyone who is not an authorised user. 
Articles in PresS. J Appl Physiol (June 9, 2016). doi:10.1152/japplphysiol.00429.2016

Kraemer et al. JAPPL-00429-2016 R-1

\section{The Effects of a Roundtrip Trans-American Jet Travel on Physiological Stress, Neuromuscular Performance and Recovery}

William J. Kraemer ${ }^{1}$, David R. Hooper ${ }^{1}$, Brian R. Kupchak ${ }^{3}$, Catherine Saenz ${ }^{1}$, Lee E. Brown ${ }^{2}$, Jakob L. Vingren ${ }^{4}$, Hui Ying Luk ${ }^{4}$, William H. DuPont ${ }^{1}$, Tunde K. Szivak ${ }^{1}$, Shawn D. Flanagan ${ }^{1}$, Lydia K. Caldwell ${ }^{1}$, Daniela Eklund ${ }^{6}$, Elaine C. Lee ${ }^{7}$, Keijo Häkkinen ${ }^{6}$, Jeff S. Volek ${ }^{1}$,

Steven J. Fleck ${ }^{5}$, and Carl M. Maresh ${ }^{1}$

${ }^{1}$ Department of Human Sciences, The Ohio State University, Columbus, OH, USA

${ }^{2}$ Department of Kinesiology, California State University-Fullerton, Fullerton, CA, USA

${ }^{3}$ Uniformed Services University of Health Sciences, Bethesda, MD, USA

${ }^{4}$ Department of Kinesiology, Health Promotion and Recreation, University of North Texas, Denton, TX, USA

${ }^{5}$ Department of Kinesiology, University of Wisconsin-Eau Claire, Eau Claire, Wisconsin

${ }^{6}$ Department of Biology of Physical Activity, University of Jyväskylä, Jyväskylä, Finland

${ }^{7}$ Department of Kinesiology, University of Connecticut, Storrs, CT, USA

Running Head: Trans-American Jet Travel and Performance

William J. Kraemer, Ph.D.

Professor

Department of Human Sciences

The Ohio State University

A054 PAES Building

305 Annie and John Glenn Avenue

Columbus, $\mathrm{OH} 43210$

614-688-2354Office

614-688-3432 Fax

kraemer.44@osu.edu 


\section{Abstract}

The purpose was to examine a round trip trans-American jet travel on performance, hormonal

2 alterations, and recovery. Ten matched pairs of recreationally trained men were randomized to

3 either a compression group (COMP) $(\mathrm{n}=10$, age: $23.1 \pm 2.4$ years, height: $174.8 \pm 5.3 \mathrm{~cm}$, body

4 mass: $84.96 \pm 10.16 \mathrm{~kg}$, body fat: $15.3 \pm 6.0 \%)$ or control group (CONT) $(\mathrm{n}=9$, age: $23.2 \pm 2.3$

5 years, height: $177.5 \pm 6.3 \mathrm{~cm}$, weight: $84.35 \pm 8.99 \mathrm{~kg}$, body fat: $15.1 \pm 6.4 \%$ ). Subjects flew

6 directly from Hartford, CT to Los Angeles, CA one day prior to a simulated sport competition

7 (SSC) designed to create muscle damage and returned the next morning on an overnight flight

8 back home. Both groups demonstrated jet lag symptoms and associated decreases in sleep

9 quality at all time points. Melatonin significantly $(\mathrm{P}<0.05)$ increased over the first two days

10 and then remained constant after the SSC. Epinephrine, testosterone, and cortisol values

11 significantly increased above resting values before and after the SSC with norepinephrine

12 increases only after the SSC. Physical performances significantly decreased from control values

13 on each day for the CONT group with COMP group exhibiting no significant declines. Muscle

14 damage markers were significantly elevated following the SSC with the COMP group having

15 significantly lower values while maintaining neuromuscular performance measures that were not

16 different from baseline testing. Trans-American jet travel has a significant impact on parameters

17 related to jet lag, sleep quality, hormonal responses, muscle tissue damage markers, and physical

18 performance with an attenuation observed with extended wear compression garments.

19 Key Words: muscular performance, circadian patterns, power, speed, endocrine system, 20 neuromuscular 


\section{New \& Noteworthy}

22 This study demonstrated trans-American jet travel going from east to west to participate in a

23 rigorous simulated sport competition had dramatic effects on hormonal responses, sleep quality

24 and neuromuscular performances. Return travel to the east after the simulated sport competition

25 resulted in muscle tissue damage and delays in neuromuscular and muscle tissue recovery upon

26 return home. The use of extended wear whole body compression garments reduced the recovery

27 times upon the homebound arrival. 


\section{Introduction}

If anyone has ever been in a plane for over 5 hours it might be obvious that there is a great deal of stress and what we understand about this phenomenon is woefully lacking. Thus, due to the dramatic impact on human physiology, jet travel across multiple time zones has been a topic of some interest $(24,33)$. However our understanding of jet travel on performance and recovery after intense exercise stress is less understood. In part, this is due to the need for an extensive and costly experimental undertaking to investigate such questions.

While the disruption of the body's circadian mechanism is most notably reflected in the changes in the pineal gland's secretion of melatonin, which is sensitive to established light-dark cycles $(1,11)$, a multitude of other factors can contribute to travel fatigue and exacerbate the magnitude and duration of "jet lag" (33). Jet lag can result in a sensation of disorientation as well as other symptoms including tiredness, inability to sleep at the normal time in the new time zone, loss of concentration, loss of psychological drive, headaches and general malaise (29). However, sleep loss appears to be one factor that may mediate many of the fatigue symptoms of jet lag and primarily contribute to performance decrements (37).

Although the concept of jet lag is well established, its effects on physical performance have not been well studied. At present, only a small number of studies have observed these effects and the parameters that have been assessed are diverse, including running speed alone (6), sprint and middle-distance performance (45), grip strength and reaction time (30) and subjective assessments of training quality (25). However, these studies examined the effects of long-haul 
49 flights traversing relatively large time zone changes, ranging from 5-8 time zones crossed. In 50 addition to long-haul flights, performance decrements have been suggested to occur when as few

51 as 2-3 times zones are traversed $(3,16,36,38)$. However, these studies observed and analyzed

52 the effects of travel on the results of athletic competitions, and did not include direct scientific 53 study of performance or its associated physiological mechanisms.

Support for possible impairments in performance from shorter flights comes from the suggestion that the time required to recover from symptoms of jet lag is approximately half a day

57 per time zone westward, and 1 day per time zone eastward (15). In this case, a 3 hour time zone 58 change eastward would require 3 days of recovery. This would be of concern to professional and 59 collegiate sport teams in the United States and other countries, because frequently travel across 3 60 times zones occurs shortly before an athletic event, either due to condensed schedules or 61 regulations of the sport governing bodies, such as the National Collegiate Athletic Association 62 (NCCA). It has been suggested that jet lag and performance decrements may occur with short 63 flights traversing 2-3 times zones primarily due to sleep disruption $(2,3)$. This is may be due to 64 the fact that melatonin concentrations will not be increased enough at the time of the event of 65 impact performance and therefore other mechanisms such as sleep loss may be playing a role to 66 negatively affect performance $(2,3,11,25)$. potentially negatively affecting performance, but the recovery processes that are required 70 following an athletic event may also be hindered on the return flight. As trans-American jet 
71 travel takes approximately 5-6 hours, and is coupled with limited space available for many

72 passengers traveling in economy class on commercial flights, travelers are forced into prolonged

73 periods of sitting with little movement. Such prolonged periods of sitting have been shown to

74 lead to significant reductions in thigh and calf blood flow, with concomitant increases in calf and 75 thigh blood pooling (34). These hemodynamic effects could drastically impair performance 76 upon arrival in a time zone as well as the ability to recover upon return to the original time zone.

Addressing the recovery process of skeletal muscle from strenuous exercise which

79 produces tissue damage has been thought to be an important concern for many individuals who 80 routinely travel for athletic competitions or strenuous recreational activities (24). Apart from

81 pharmaceutical interventions that have been used to assist in recovery, prior research on 82 compressive garments have shown promise in helping in recovery and provided an interesting 83 and unique experimental secondary dimension to our understanding of jet-lag/travel stress (18, $8420,27,40)$. The physiological effects of such compressive therapy after damaging exercise has 85 been shown to reduce indirect markers of skeletal muscle tissue damage and allow performance 86 recovery at a more rapid rate $(18,19,27)$. Such an effect would appear beneficial to trans87 American jet travel when highly stressful exercise is performed prior to returning home from 88 competitive or recreational events. Consistent with our prior research, we hypothesized that 89 within the jet-lag/travel stress model we used, enhanced recovery would be possible using 90 extended wear of compression garments. 
Our current understanding of the associated hormonal responses to actual trans-American

93 jet travel resulting in jet lag and travel stress beyond the obvious focus on melatonin secretion

94 remains unclear and imprecise at best. It is well established that several endocrine factors

95 display distinct circadian oscillations, which are controlled by both endogenous factors and

97 wake-cycles (10), imposed by jet lag/travel stress. Considering the role of epinephrine, norepinephrine and cortisol in preparing the human body for an increased need for alertness and energy demands prior to physical activity, avoiding disruptions in the circadian cycles may be crucial for athletic populations traveling across several time zones shortly prior to athletic events.

The catecholamines epinephrine and norepinephrine both display similar circadian patterns, with the lowest levels occurring during nighttime. While the norepinephrine rhythm is strongly dictated by changes in posture and the sleep-wake -state, the circadian oscillation of epinephrine does not appear to be as strongly dictated by the same variables (26). Cortisol release, with the peak occurring in the morning (41), displays a lower sensitivity to behavioral changes, likely indicating strong endogenous regulation similar to epinephrine $(8,10)$. However, the effect of time-zone travel on these endocrine factors has not been previously established. 
114 processes following demanding physical activity and determine whether a compression garment 115 intervention can ameliorate any of tissue damage effects upon return to the original time zone.

117 Methods

This study design represented an extensive and comprehensive examination of transAmerican travel. A detailed schedule is presented in Table 1. A battery of physiological, 121 psychological, and physical performance tests were administered during a United States east 122 coast to west coast and return travel schedule. After extensive familiarization, baseline testing 123 was performed the day before travel. Subjects were asked not to ingest any alcohol during the 124 course of the study. Similar to our prior muscle damage studies after the simulated sporting 125 event creating muscle damage subjects were ask to refrain from the use of any medication or 126 extended showers. For all testing each of the participants wore their same athletic equipment 127 including shoes. The schedule developed would be typical for many NCAA teams of athletes 128 following NCAA regulations, who are based in the northeast United States participating in 129 competitions on the west coast. We used this team approach in conducting our investigation as 130 typical to schedules and organization of event sequences in order to provide insights and 131 generalizations to multitude of similar jet travel to and from recreational and competitive events 132 each year in the United States. 
136

138

139

140

141

142

143

144

145

146

147

148

149

150

151

152

153

154

155

Participants

Following a detailed explanation of study procedures as well as the risks and benefits involved in the study, all participants provided informed consent prior to the start of the study. The study was approved by the university's Institutional Review Board for use of human subjects in research. Ten pairs of subjects were matched for Ponderel Index and body fat percentage and activity backgrounds and then randomized into one of two groups. Body composition was measured by a trained technician via the 3 site Jackson-Pollock skinfold technique (14). One subject could not make the flight and thus nineteen recreationally trained men (i.e., had been weight training and endurance training for over 6 months) participated in the study consisting of either a compression group (COMP) $(n=10$; age: $23.1 \pm 2.4$ years, height: $174.8 \pm 5.3 \mathrm{~cm}$, body mass: $84.9 \pm 10.1 \mathrm{~kg}$, body fat: $15.3 \pm 6.0 \%)$ or control group (CONT) ( $\mathrm{n}=9$; age: $23.2 \pm 2.3$ years, height: $177.5 \pm 6.3 \mathrm{~cm}$, weight: $84.3 \pm 8.99 \mathrm{~kg}$, body fat: $15.1 \pm$ 6.4\%). While no formal training study was undertaken with the subjects in the investigation, each of the subjects reported to have been involved with progressive heavy resistance training with complementary endurance training, each performed 3 to 4 times a week. Resistance training was characterized by periodized, multiple sets, whole body, large muscle groups exercises with targets for muscle strength and size. Subjects were former high school and college athletes who participated in a variety of sports including football, basketball, track and field, wrestling, baseball and some were former warfighters in the military who were all accustomed with intense weekly physical training routines. 
After randomization the groups were supplied with two sets of either loose fitting apparel or compression garments so that they could be laundered during the study time frame. The 162 garments were worn after the first baseline testing session and continued to be worn for the entire 163 experimental time frame. The compression garments had been designed for long term wear.

164 The garments were worn at all times during the study (including sleep) except during the 165 simulated sporting event (muscle damage protocol), during brief showers, or when blood draws 166 were obtained. The compression garments used was the Under Armour Recharge ${ }^{\mathrm{TM}}$ upper and 167 lower body garments constructed to produce needed compression and to allow long-term wear 168 with comfort (75\% nylon and 25\% spandex) [Under Armour, Baltimore, MD, USA]). In this 169 study we used the Under Armour Recharge ${ }^{\mathrm{TM}}$ long sleeve shirt lower body leggings for easy use 170 in everyday activities. All testing and the simulated sport competition took place without the use 171 of the garments. Prior work on the Under Armour Recharge ${ }^{\mathrm{TM}}$ whole body suit had been 172 previously shown to effectively improve recovery after high intensity resistance training 173 workouts (20). 
We used an extensive familiarization process prior to data collection. Familiarization sessions (i.e., 3-4 as needed before the final Day 1 familiarization session, see Table 1) were conducted with the participants to reduce or limit learning effects. During these sessions each participant practiced the test so that each participant was fully familiarized with each of the testing procedures. Each participant had all questionnaires explained to them and investigators answered questions so that they understood the different elements of each questionnaire. The participants took the questionnaires with them to further familiarize themselves with the questionnaires and were allowed to ask any subsequent questions that arose for proper completion.

\section{Controls}

All participants were non-smokers and had not used any anabolic drugs and were cleared medically by a physician so as not to have any clinical, orthopedic, or pathological conditions that would confound the effects of the study. In addition, subjects were requested to refrain from taking any oral pain medications including NSAIDs during the study and to abstain from any normal heavy lifting for a period beginning 3 days prior to the study. After completing the simulated sporting event, subjects were asked to limit water temperature and duration when bathing, to abstain from physical activity other than those activities required during daily living tasks, and to use no pain-relieving modalities including heat, ice, or massage during the study. In addition, a registered dietician monitored food intakes and screened subjects for any usual diets or supplements which might have compromised or confound the variables measured in the study. Normal caffeine intakes were observed and no attempt was made to limit caffeine ingestion as only water was allowed $4 \mathrm{hrs}$ prior to testing. 


\section{Testing Battery}

Urine and Blood Sampling

203 Prior to the physical testing battery, urine and blood samples were collected.

Urine Samples: Upon arrival to the laboratory, participants provided a urine sample and

205 hydration state was confirmed by measurement of urine specific gravity (USG) with a handheld 206 refractometer (Reichert, New York, NY). A USG $<1.020$ indicated euhydration. Due to 207 frequent verbal instructions to keep hydrated and to drink 0.5 liters of water at night and in the 208 morning almost all subjects met this requirement before all testing sessions during the study. If 209 USG was $>1.020$, then participants were instructed to drink water until their USG was $<1.020$.

Blood Samples: An indwelling Teflon cannula was inserted by a trained phlebotomist

212 into superficial antecubital forearm vein and after sitting quietly for 10 minutes in the seated 213 position a $33 \mathrm{ml}$ blood sample was collected from a vacutainer set-up into serum (10ml), EDTA 214 (10ml), $\mathrm{Na}$ citrate $(5 \mathrm{ml})$ and $\mathrm{Na}$ Heparin $(8 \mathrm{ml})$ tubes. Serum and plasma samples were 215 immediately centrifuged at $1,500 \mathrm{~g}$ for $15 \mathrm{~min}$ at $4^{\circ} \mathrm{C}$ aliquoted in to appropriately sized and 216 labeled Eppendorf tubes and stored at $-80^{\circ} \mathrm{C}$ until subsequent analyses. Samples were thawed 217 only once for analysis. All blood samples were performed in duplicate analyses.

Total creatine kinase was measured in duplicate from serum samples using liquid creatine 
221 instructions. Intra-and inter-assay coefficients of variations for creatine kinase were below 3.9\%.

222 Myoglobin was measured from EDTA-plasma in duplicate via enzyme linked immunosorbancy 223 assay (ELISA) (CALBiotech, Spring Valley, CA). The mean intra-assay coefficients of 224 variation $(\mathrm{CVs})$ were $5.6 \%$ and inter-assay coefficients of variation were $7.9 \%$.

225

226

227

228

229

230

231

232

233

234

235

236 237 norepinephrine, respectively. respectively.

All ELISAs were performed on a VersaMax tunable microplate reader (Molecular Devices, Sunnyvale, CA) at the appropriate wavelength for that particular assay and customized data analytics. Cortisol and total testosterone were measured by ELISA from serum (CALBiotech, Spring Valley, CA). The intra-assay coefficients of variation were $5.4 \%$ and $4.1 \%$ and the inter-assay coefficients of variation were $6.8 \%$ and $7.6 \%$ for cortisol and testosterone,

Epinephrine and norepinephrine were extracted from serum samples and acylated according to manufactures instructions (ALPCO Diagnostics Salem, NH). The prepared samples were then measured by ELISA. The intra-assay coefficients of variation were $8.1 \%$ and $3.6 \%$ and the inter-assay coefficients of variation were $10.8 \%$ and $5.8 \%$ for epinephrine and 
Per Table 1, when specific time frame physical performance testing was to be performed,

243 it followed the urine and blood sampling procedures. Prior to the testing battery being 244 administered, each participant performed a warm-up protocol. The warm-up included 5 minutes 245 on a cycle ergometer with light resistance and a constant speed of 60rpm. This was followed by 246 a series of standard dynamic stretches, including forward lunges, lateral lunges, knee hugs, quad 247 pulls and straight leg march.

Countermovement Vertical Jump: While typical in many athletic testing facilities and in 250 order to have identical equipment set ups in each laboratory, a Vertec device (JumpUSA, 251 Sunnyvale, CA) was used to measure vertical jump capabilities. Participants stood with feet hip 252 width apart directly under the Vertec before performing a rapid countermovement and jumping 253 with maximal effort. Participants were instructed to reach the highest possible vane with their 254 dominant hand. About 2 to 3 minutes rest was taken between attempts and the highest jump 255 height was used for subsequent analysis.

Hand Grip Strength: This measure was determined using a hand grip dynamometer. 258 Participants stood with feet hip-width apart and shoulders level. The dynamometer (T.K.K.5401 259 GRIP-D [DIGITAL GRIP DYNAMOMETER, Niigata City, Japan) was held in their hand with 260 their dominant (i.e., determined by what hand they write with and throw a ball the furthest with) 261 arm hanging straight down at their side with no bend in the elbow. Each subject was allowed 262 three attempts with the best of the three attempts used for analysis. From our work with 263 NHANES we used the same testing protocol as described (i.e., chapter 3) for grip strength 
264 (http://www.cdc.gov/nchs/n(nyfs/manuals.htm). Each subject was tested on the same calibrated 265 dynamometer over the course of the study at both testing sites.

Quickness and Reaction: Per Table 1, the Quick Board ${ }^{\mathrm{TM}}$ test was only performed at the 268 Human Performance Laboratory in CT before and after the air travel. The Quick Board ${ }^{\mathrm{TM}}$ 269 system (Memphis, TN) was used to measure foot quickness and reaction time of lower body 270 stepping movements (17). Briefly, the Quick Board ${ }^{\mathrm{TM}}$ system is comprised of a visual stimulus 271 board with five lights consisting of two on the top, one in the middle and two on the bottom and 272 a corresponding step pad on placed on the ground. Once the test began, one of five lights 273 illuminates. The participant then steps on the pad located on the floor that corresponds to the 274 light in the same position. Once the participant stepped on the correct pad, a new light

275 illuminated. If the participant steps on an incorrect pad, a buzzer sounded and the participant 276 was required to contact the correct pad before a new light would appear. The test continues for 27710 seconds and the number of correct were recorded and used for analyses in this investigation. 278 About one minute rest was taken between trials and in this study the best score of three trials was 279 used for analysis. 284 this drill. The subject starts the drill running for 5 yards $(4.572 \mathrm{~m})$ to the right, touches the line 285 and then changes direction and runs 10 yards $(9.144 \mathrm{~m})$ to the left and touches the line and then 
286 runs 5 yards (4.572) straight through the finish line. Each participant had three trials with about 2875 minutes rest between trails with and the fastest time used for analysis.

292 in this drill (28). Approximately 5 minutes rest was taken between two trials. The faster of the 293 two trials was used for analysis.

Perceptual Testing

297 perception of jet lag) were reported by completing the LJLQ (43) each evening and morning 298 during the data collection period. This questionnaire was designed to measure all of the 299 symptoms of jet lag at different times of day and is a common validated tool used to assess jet 300 lag in athletes and was the underlying reason why we chose to use it in this study (44). 301 Questionnaires for each day of the investigation were collected by the research team.

Travel -Connecticut to California:

Baseline testing was performed the day before travel starting at $1300 \mathrm{hrs}$ ET. The entire 305 research team and all participants traveled together during the entire investigation similar to an 306 athletic team. Study participants arrived at the Human Performance Laboratory at the 
307 University of Connecticut at 05:00 ET. For both the East and West bound flights, all subjects 308 went through the Transportation Security Administration |(TSA) security check points but the 309 lines were not long and time to make it through the process was not excessive but was an added 310 component of the travel stress. Following urine and blood sampling at 0600 ET, participants 311 were transported by chartered bus for 30 minutes to Bradley International Airport (BDL) in 312 Hartford, CT for the departing flight at 09:00 ET. The flight was direct to Los Angeles 313 International Airport (LAX) flying on a Boeing 737-800 airliner with participants traveling in 314 coach class, randomly ticketed throughout the plane in coach class with a travel time of $6 \mathrm{hrs}$ and 31520 minutes arriving at 12:20 PT. Participants were then transported by another chartered coach 316 to the Human Performance Laboratory at California State University-Fullerton, for testing with 317 a travel time of 1 hour. Participants changed and rested in the locker rooms and prepared for 318 testing which began at $1500 \mathrm{hrs}$ PT.

Upon completion of the testing, participants showered and changed and were transported to the campus hotel and were checked into their rooms. As with a team, a group dinner was 322 scheduled at 1830 hrs. After dinner, all participants were instructed as to the schedule for Day 2, 323 rested in the hotel and instructed to turn in by 2200 hrs to get ready for the next day's events. 
329 laboratory for testing. Per Table 1, testing of the participants started at $1300 \mathrm{hrs}$ PT with the 330 research team and was completed in preparation for the "simulated sporting event" by $1400 \mathrm{hrs}$ 331 PT.

Simulated Sporting Event

At 1400 hrs PT all of the participants gathered at an outdoor grass athletic field on the campus of California State University - Fullerton to participate in an intense exercise protocol to simulate an athletic event. At the onset of the exercise protocol the temperature was $21.6{ }^{\circ} \mathrm{C}$

$337\left(71^{\circ} \mathrm{F}\right)$ and an average humidity for the day at $63 \%$. The participants completed the following exercises designed to simulate the muscle damage due to physical activity that would occur during a high-intensity intermittent sporting event such as soccer. The exercise was performed as the total group on the field with an exercise leader and other members of the research team cheering and encouraging performances. A lot of verbal encouragement within the group created 342 a highly aroused environment for the exercise protocol. We added additional plyometric and 343 eccentric exercise stress to a repeated sprint protocol already shown to produce significant 344 muscle tissue damage (13). Our protocol consisted of five sets of 10 repeated maximal effort 345 countermovement jumps, 5 sets of 10 plyometric push-ups, 5 sets of 10 Nordic hamstring curls 346 and 5 sets of 10 standard pushups. All exercises were performed with 60 s rest between sets. 347 These exercises were followed by the repeated sprint protocol (13). Subjects performed $1520 \mathrm{~m}$ 348 sprints with a maximum of $10 \mathrm{~m}$ deceleration distance (thereby producing eccentric damage). 349 Sprints were performed on the minute, therefore the rest period between sprints was the time 350 remaining in each minute. At the completion of the simulated sporting event the participants 
351 immediately returned to the laboratory at $1500 \mathrm{hrs}$ PT for post-event urine and blood sampling.

352 After testing participants prepared for travel back to CT.

\section{California to Connecticut:}

The research team and participants left California State University Fullerton at 20:00 hrs

PT, where they were then transported by coach for 1 hour back to LAX for the departing flight at 23:30 hrs PT. The flight was direct to Bradley International Airport in Hartford CT (BDL) again flying on a Boeing 737-800 airliner with participants traveling in coach class, randomly ticketed

359 throughout the plane in coach class with a travel time of 5 hours and 20 minutes, which arrived at 07:50 hrs ET. Participants were transported by chartered bus for 30 minutes back to the Human Performance Laboratory at the University of Connecticut for post-travel testing. Per

362 Table 1, at $0900 \mathrm{hrs}$ ET following air travel from California, post-West coast testing was initiated. The entire testing battery was performed staring with urine and blood sampling ending with the 40 Yard Sprint $(36.576 \mathrm{~m})$ testing. Each participant then showered and dressed and were then again instructed not to use any external showers, alcohol or drugs during the recovery 366 period and when to report the next day to the laboratory for final testing.

The next day at 13:00 hrs ET subjects reported to the laboratory for the final set of tests to complete the investigation. All subjects had been instructed to follow the same schedule in

371 the morning with a 7:00 to 8:00 ET breakfast and then again as with the 13:00 hrs testing 372 consume only water to remain hydrated. The entire test battery was again completed and all 
373 questionnaires were documented to have been completed and handed into the research team.

374 Each of the subjects was then follow-up on over the next few days to assure that they were 375 satisfactorily recovered. No injuries or adverse events occurred over the course of the 376 investigation.

\section{Statistical Analyses}

3790.83 to 0.96 for the n sizes used in the study (nQuery Advisor; Statistical Solutions, Saugus, MA, 380 USA). Reliability range for the dependent variables intra-class correlation coefficients were $\mathrm{R} \geq$

3810.85 . We met all statistical assumptions for linear statistics. Any variables that did not meet this 382 assumption were logarithmically $\left(\log _{10}\right)$ corrected and tested again. An independent t-test was 383 used to compare demographic characteristics between the experimental groups and no significant 384 differences were observed with the matching process. The statistical evaluation of the 385 experimental data was accomplished using a 2-way analysis of variance with repeated measures 386 for treatment and time. When appropriate, Fisher's LSD post hoc tests were used to determine 387 pairwise differences. A $\mathrm{p} \leq 0.05$ was defined as being statistically significant. 
$389 \quad$ Results

390

391

392 through the entire experimental period no changes were observed over time or between groups

393 for the grip strength measure. No significant main effects or interactions effects were observed 394 for grip strength.

395

396

397

398

399

400

401

402

403

404

405

406

407

408
Physical Performances

The physical performance testing can be observed in Table 2. From the baseline (BL)

Table 2 about here

\section{Countermovement Vertical Jump}

Significant main effects and interaction effects were observed for the CMJ performances. In the CONT group a significant decrease in the countermovement vertical jump (CMJ) height was observed upon arrival at the west coast on day 2 and differences from BL continued through the rest of the experimental time period through day 5. For the COMP group no significant differences from BL were observed over the experimental period yet jump height was significantly higher from the CONT group on day 3 prior to the simulated sporting event and remained higher on days 4 and 5 upon return to the east coast. 
411 5) (PAD). Significantly slower times were observed in the CONT group upon arrival at the west 412 coast on day 2 and this difference from BL continued through days 3 and 4 but recovered to BL 413 values on recovery day 5 back on the east coast. No significant changes were observed for the 414 COMP group from BL over the entire experimental period but at each time point after arrival on 415 the west coast the times were significantly lower than the CONT group.

41740 Yard Sprint (36.576 m)

420 Thus high speed locomotor capabilities demonstrated similar changes again with significant 421 main effects and interaction effects for the testing. The 40YS showed significantly slower times 422 upon arrival at the west coast on day 2 when compared to the BL testing for the CONT group. 423 This difference from BL continued through until the final recovery day 5 testing back on the east 424 coast when no differences from BL were observed. No significant changes were observed for 425 the COMP group from BL testing over the entire experimental period but again at each time 426 point after arrival on the west coast on day 2 the times were significantly faster than the CONT 427 group. 
The testing for quickness and reaction of the lower body using the Quick Board was

431

432

433

434

435

436

437

measured only at BL and then again on days 4 and 5 after return to the east coast. In contrast to the locomotor speed tests the CONT group saw a greater number of correct touches when compared to BL when they arrived back to the east coast on day 4 testing but on day 5 no significant differences were observed from BL. The COMP group saw no significant changes from BL however on day 4 demonstrated fewer correct touches than the CONT group.

\section{Psychological and Testing}

Table 3 shows the results of the Liverpool Jet Lag Questionnaires (LJLQ) over the experimental time period. The perception of jet lag manifested itself significantly higher than the Day 1 PM measure on the evening (PM) of Day 2 and while fluctuations occurred this perception remained significantly elevated until getting a night's sleep before the morning (AM) of Day 5 . No differences were observed between the two experimental groups.

The fatigue perceptions of the participants did not significantly change over Day 1 PM to Day 2 AM. A significant increase in perceived fatigue occurred in both groups in the evening of Day 2. Recovery occurred in the morning of Day 3 AM but was again significantly elevated on the evening of Day 4 after which the simulated sporting event was held that afternoon. The fatigue levels remained significantly elevated on the morning of Day 4 after the "overnight" flight. Some reduction by the PM of Day 4 occurred but after a night's sleep, fatigue levels returned back to what had been observed at the beginning of the study on Day 1. There was no differences observed between the groups. 
Before the subjects went to sleep in the evenings rated their perception of how well they 453 would sleep with the higher number indicative of expectations of good sleep. After arriving on

454 the west coast participants had significantly higher expectations for good sleep on the night of 455 Day 2. The only group differences occurred on the night of Day 3 where the CONT group felt 456 they would gain much better sleep than other nights but the COMP group, potentially due to 457 feeling the effects of the damage being compressed did not feel they would sleep very well that 458 night. However, each group returned to Day 1 values which revolved around the neutral zero 459 rating on the scale. Over the entire experiment the actual perceived quality of sleep revolved 460 around the neutral Likert scaling of around 0. However, the actual quality of the sleep was 461 negatively rated after in the morning of Day 4 upon return to the east coast after the "overnight" 462 flight. No significant differences were observed between the groups.

\section{Table 3 about here}

464

465

466

\section{Hormonal Responses}

Figure 1 presents the responses over the experimental period the responses of plasma epinephrine and norepinephrine along with melatonin.

Catecholamines are presented in the first two panels. For plasma norepinephrine, significant elevations were observed only after the simulated sport competition (i.e., postdamage) on Day 3. All other concentrations were similar to baseline values. No experimental group differences were observed. For plasma epinephrine, significant elevations over baseline and other time points were observed before and following the simulated sport competition (i.e., post-damage). Interestingly, the values for each of the other time points were a bit higher than typically observed at resting conditions reflecting the potentially enhanced adrenergic 
474 stimulation with the overall set of stressors in young men (21). No differences were observed 475 between the groups.

476

477

478

479

480

481

482

483

484

485

486

487

488

489

490

491

492

493

494

495
Plasma melatonin is presented $\mathrm{n}$ Figure 1 in the third panel. Melatonin concentrations were significantly higher than baseline on Day 2 AM at 6:00 hrs. Significant elevation over baseline were again observed on Day 4 AM upon return to east coast. No differences were observed between groups.

\section{Figure 1 about here}

Figure 2 presents the indirect markers of muscle tissue damage over the time frame of the experimental design for the two treatment groups. Creatine kinase in the first panel shows that the values were not elevated over baseline values until after the simulated sport competition (i.e., post-damage) on Day 3. These values remained significantly elevated above baseline values at each of the remaining time points for both treatment groups. These elevations were significantly higher than other times points after the baseline values. However, there was a treatment difference with the CONT group demonstrating significantly higher values than the COMP group for each time point after the simulated sport competition onward indicating an effect of the compression therapy. Myoglobin concentrations showed elevations above resting baseline values after the simulated sport competition on Day 3 with small elevation in the CONT group on Day 4. All elevations were also greater than other time points as well. Differences between the treatment groups was again noted on Day 3 with the COMP group significantly lower than the control group reflecting the influence of the compression therapy.

Figure 2 about here 
Figure 3 presents the serum cortisol and testosterone values in two panels over the

497

498

499

500

501

502

503

504

505

506

507

508

509

510

511

512

513 differences are similar to previous research demonstrating impaired performance following 514

515

516

Figure 3 about here

\section{Discussion}

With the high number of short term trips (3-4 days) requiring trans-American jet flights that occur for individuals or athletes participating in strenuous competitive athletic or recreational events, few data are available to simultaneously document the physiological, perceptual, and performance effects and/or offer additional solutions to potential problems associated with the concept of jet lag. The primary finding of this study is that travelling westbound 3 times zones can have a significant effect on power, agility and speed performances in physically trained young men if performed both immediately following, as well as approximately 24 hours following arrival, at least in the case of the CONT group. These traversing a greater number of time zones of 5-8 time zones $(25,30,45)$. Although prior studies have observed team performances in sporting competitions $(3,16,36,38)$, this is the first study to identify the specific parameters that are affected following travel across 3 time zones. 
The mechanism that has been proposed to cause these performance disturbances is the phenomenon known as jet lag, where via circadian disruption sleep is impaired, general fatigue is increased and cognitive and physical performance degrades. Much like prior research, this study showed significant jet lag, fatigue and reduced sleep quality following a westbound flight. In the CONT group only, the psychological effects, indicated by the LJLQ, were manifested as negative effects on physical performance with reductions in power, agility and speed shown in Table 2.

We were particularly interested in the physiological mechanisms as mediated by hormonal responses which may help in our understanding of the jet lag phenomenon and its effects. What has not been identified in prior work is the hormonal milieu that is a consequence of the circadian disruption and is associated with the changes in jet lag phenomenon and physical performance. As can be seen in Figure 1, adrenergic responses were not significantly elevated until just prior to the anticipation of impending physical activity as represented in this study as a simulated sport competition workout. Prior studies have shown that anticipatory stress of physical activity is a dramatic physiological regulation of the "fight-flight" response $(9,22)$. Interestingly, norepinephrine did not significantly elevate until after the exercise stress again representing the more sympathetic neural demands of the workout. The highly specific adrenal medullary pre-exercise response supports the neuropsychological stimulated release of epinephrine and the lower concentration of norepinephrine content in the adrenal medulla secretions $(<10 \%$ of adrenal medulla content). The observation that epinephrine concentrations may have been a marginally elevated over the entire experimental protocol compared to our prior extensive measurement of resting values (i.e., typically under $200 \mathrm{pmol} \cdot \mathrm{L}^{-1}$ ) may reflect some 
540 of the more subtle travel stress that was perceived by the subjects with fatigue and sleep 541 disturbances that existed (21).

Melatonin concentrations reflect release of the hormone by the pineal gland which is 543 regulated by the light/dark information from the eyes where retinal photosensitive ganglion cells 544 exist and produce the shrouding effects upon or waking from sleep $(31,32)$. Significant 545 elevations were observed the morning of the westbound trip at 6:00 hrs most likely due to the 546 morning circadian time frame as norepinephrine did not provide any additional stimuli (32). The

547 lack of any melatonin increases at the time of performance testing prior to the damage protocol 548 suggests that the influence of any light/dark cycle or weariness characteristic of pre-sleep time 549 frames were not present and would have been off-set by adrenal adrenergic pre-exercise effects 550 (17). For the most part the AM and PM values reflected what might be expected with light/dark 551 cycles and sleep. The higher melatonin values prior to the westbound trip were concomitant with 552 better sleep quality perception by the subjects. Whereas the lower elevations observed at 9:00 553 hrs following the eastbound late night "overnight" flight and transport to the laboratory were 554 concomitant with much lower sleep quality from the prior night on the morning of Day 4. This 555 combination of time and travel may have altered the circadian pattern of melatonin upon waking. 556 No treatment group effects were observed for melatonin reflecting the lack of any differential 557 effects long wear compression therapy. Circadian disruptions have been implicated in jet-lag 558 induced performance attenuations, these disruptions do not appear to apply to the adrenergic 559 response or melatonin, upon the arrival out west for Day 2 testing. The decline in performance 560 in the CONT group cannot be attributed to sleep deprivation, as this was not significantly 561 affected the morning prior to the flight. The only explanation of the performance data on Day 2 
562 in the CONT group was that they reported several hours later to be suffering significant jet lag 563 and fatigue, and expected to sleep poorly the next night (Table 3, Day 2 PM).

564

565

566

567

568

569

570

571 572 as 24 hours following the westbound flight (42).

Despite a substantial adrenergic response on Day 3 concomitant with no changes in melatonin, it might be postulated that physical performance related to power, agility and speed would not decline as observed in the CONT group (17). Conversely, the COMP group demonstrated no significant physical performance differences from baseline testing and also showed significantly better performances than the CONT group at the corresponding time points. Thus it could be speculated that the enhanced venous return due to wearing the compression garments with adequate pressure was having a notable effect immediately upon arrival, as well

573

No studies have really examined the effects of long term wear compressive garments 575 making the reasons for the performance maintenance over the westbound travel open to 576 speculation. A variety of reasons might be proposed including such concepts as increased 577 oxygenation of muscle, better toleration to airline coach travel with regards to resting circulatory 578 dynamics and oxygenation, and/or better muscle repair from confined limb stress configurations $579(5,7,40)$. What is fascinating is that despite significant jet lag, fatigue and perceptions of poor 580 sleep quality, as well elevated melatonin the COMP group continues to show no reductions in 581 any parameters of physical performance, indicating to the potential importance of maintaining 582 blood flow during recovery as well as during long periods of travel. 
Consistent with ours and other investigative studies the performance of the COMP group 585 following the simulated game was to be expected, due the substantial enhancement of the 586 recovery process that has been shown previously due to compression garments $(18,20)$.

587 Different from prior work, this study used the same garments in an extended wear context. As 588 can be seen in Figure 2, the COMP group demonstrated significant attenuations in markers of 589 muscle damage immediately following the simulated event, as well as immediately following the 590 eastbound return trip, and even 24 hours following arrival on the East Coast. The higher markers 591 of muscle damage in the CONT group likely reflect the damage to the muscle tissues' myosin 592 motors in part mediating the significantly reduced power, agility and speed performance in 593 comparison with the COMP group $(19,20)$.

As expected, cortisol and testosterone showed significantly elevated concentrations in 596 both groups after the simulated sport competition which emphasized eccentric and decelerating 597 loads $(12,39)$. Interestingly, testosterone was again elevated following the eastbound flight 598 again in both groups suggesting a continued anabolic signaling being maintained during the 599 recovery period (see Figure 3). However, this effect in potential response to travel stress was 600 augmented by the typical diurnal variation of testosterone, with a peak between 7-10am. 601 Interestingly, cortisol was not elevated after the eastbound flight which may be due to the trained 602 nature of our test participants (23). 
606 sport enthusiasts. This study demonstrated that trans-American travel, when compared to prior 607 research traverses a relatively low number of time zones but still leads to attenuations in most 608 physical performance tests in the CONT condition immediately following the flight going in 609 both directions(2). For the most part (i.e., except for CMVJ in CONT group) recovery is 610 observed $24 \mathrm{hrs}$ after landing. Grip strength often used to represent an individual's strength 611 capability, showed no alterations and may not be a simple biomarker of performance losses. The 612 use of extended wear compression garments demonstrated remarkable effects in helping with 613 recovery from the flight stress potentially due to circulatory dynamics and from the simulated 614 sport competition most likely due to helping in muscle tissue recovery following the exercise 615 stress. Such data reflect the need for individuals traveling for competitive sport or recreational 616 competitions arrive $24 \mathrm{hr}$. prior to an event. These data also uniquely now show that the 617 performance reductions related to long distance travel are not associated with changes in 618 melatonin, or a dampening of the adrenergic response. In trans-American travel, time zone 619 adjustment is not typically recommended, therefore compression garments could be a novel way 620 to remedy athletic or recreational performance reductions following such travel. 
624

625

626

627

628

629

630

631

632

633

634

635

636

637

638

639

640

641

642

643

644

645

646

647

648

649

\section{Acknowledgements}

The authors would like to thank the research, support staff, and medical staffs at the University of Connecticut and at California State University-Fullerton for such a study involved a massive set of logistics and travel arrangements to successfully complete this unique study. This study was funded by a grant from Under Armour Inc., Baltimore, MD. The authors have no conflict of interests to declare with the funding related to this research study. The opinions and assertions expressed herein are those of the authors and should not be construed as reflecting those of the Uniformed Services University, Department of the Army, Department of the Air Force, Department of the Navy or the United States Department of Defense.

\section{Figure Legends}

Figure 1. Changes in melatonin, epinephrine and norepinephrine following westbound and eastbound Trans-American flights before and after a simulated sporting event respectively in subjects wearing non-compressive (gray bars) and full body compression (black bars) garments. $*=$ Significantly $(\mathrm{P} \leq 0.05)$ different from baseline.

Figure 2. Changes in markers of muscle damage following westbound and eastbound TransAmerican flights before and after a simulated sporting event respectively in subjects wearing non-compressive (gray bars) and full body compression (black bars) garments. * = Significantly different from baseline. \# = significantly different from corresponding COMP group.

Figure 3. Changes in testosterone and cortisol following westbound and eastbound TransAmerican flights before and after a simulated sporting event respectively in subjects wearing non-compressive (gray bars) and full body compression (black bars) garments. * = Significantly

$48 \quad(\mathrm{P} \leq 0.05)$ different from baseline. 


\section{References}

1. Altun A, and Ugur-Altun B. Melatonin: therapeutic and clinical utilization. International journal of clinical practice 61: 835-845, 2007.

2. Arendt J. Managing jet lag: Some of the problems and possible new solutions. Sleep medicine reviews 13: 249-256, 2009.

3. Bishop D. The effects of travel on team performance in the Australian national netball competition. Journal of science and medicine in sport / Sports Medicine Australia 7: 118-122, 2004.

4. Bower ME, Kraemer WJ, Potteiger JA, Volek JS, Hatfield DA, Vingren JL, Spiering BA, Fragala MS, Ho JY, Thomas GA, Earp JE, Hakkinen K, and Maresh CM. Relationship between off-ice testing variables and on-ice speed in women's collegiate synchronized figure skaters: implications for training. J Strength Cond Res 24: 831-839, 2010. 5. Bringard A, Denis R, Belluye N, and Perrey S. Effects of compression tights on calf muscle oxygenation and venous pooling during quiet resting in supine and standing positions. $J$ Sports Med Phys Fitness 46: 548-554, 2006.

6. Bullock N, Martin DT, Ross A, Rosemond D, and Marino FE. Effect of long haul travel on maximal sprint performance and diurnal variations in elite skeleton athletes. British journal of sports medicine 41: 569-573; discussion 573, 2007.

7. Coza A, Dunn JF, Anderson B, and Nigg BM. Effects of compression on muscle tissue oxygenation at the onset of exercise. J Strength Cond Res 26: 1631-1637, 2012.

8. Durgan DJ, Trexler NA, Egbejimi O, McElfresh TA, Suk HY, Petterson LE, Shaw CA, Hardin PE, Bray MS, Chandler MP, Chow CW, and Young ME. The circadian clock within the cardiomyocyte is essential for responsiveness of the heart to fatty acids. $J$ Biol Chem 281: 24254-24269, 2006.

9. French DN, Kraemer WJ, Volek JS, Spiering BA, Judelson DA, Hoffman JR, and Maresh CM. Anticipatory responses of catecholamines on muscle force production. J Appl Physiol (1985) 102: 94-102, 2007.

10. Gamble KL, Berry R, Frank SJ, and Young ME. Circadian clock control of endocrine factors. Nat Rev Endocrinol 10: 466-475, 2014.

11. Hastings M, O'Neill JS, and Maywood ES. Circadian clocks: regulators of endocrine and metabolic rhythms. The Journal of endocrinology 195: 187-198, 2007.

12. Heavens KR, Szivak TK, Hooper DR, Dunn-Lewis C, Comstock BA, Flanagan SD, Looney DP, Kupchak BR, Maresh CM, Volek JS, and Kraemer WJ. The effects of high intensity short rest resistance exercise on muscle damage markers in men and women. $J$ Strength Cond Res 28: 1041-1049, 2014.

13. Howatson G, and Milak A. Exercise-induced muscle damage following a bout of sport specific repeated sprints. J Strength Cond Res 23: 2419-2424, 2009.

14. Jackson AS, and Pollock ML. Generalized equations for predicting body density of men. Br J Nutr 40: 497-504, 1978.

15. Jackson G. Come fly with me: jet lag and melatonin. International journal of clinical practice 64: 135, 2010.

16. Jehue R, Street D, and Huizenga R. Effect of time zone and game time changes on team performance: National Football League. Medicine and Science in Sports and Exercise 25: 127-131, 1993.

17. Kraemer WJ, Boyd BM, Hooper DR, Fragala MS, Hatfield DL, Dunn-Lewis C, Comstock BA, Szivak TK, Flanagan SD, Looney DP, Newton RU, Vingren JL, Hakkinen 
K, White MT, Volek JS, and Maresh CM. Epinephrine preworkout elevation may offset early morning melatonin concentrations to maintain maximal muscular force and power in track athletes. J Strength Cond Res 28: 2604-2610, 2014. 18. Kraemer WJ, Bush JA, Wickham RB, Denegar CR, Gomez AL, Gotshalk LA, Duncan ND, Volek JS, Putukian M, and Sebastianelli WJ. Influence of compression therapy on symptoms following soft tissue injury from maximal eccentric exercise. The Journal of orthopaedic and sports physical therapy 31: 282-290, 2001.

19. Kraemer WJ, Bush JA, Wickham RB, Denegar CR, Gomez AL, Gotshalk LA, Duncan ND, Volek JS, Putukian M, and Sebastianelli WJ. Influence of compression therapy on symptoms following soft tissue injury from maximal eccentric exercise. J Orthop Sports Phys Ther 31: 282-290, 2001.

20. Kraemer WJ, Flanagan SD, Comstock BA, Fragala MS, Earp JE, Dunn-Lewis C, Ho JY, Thomas GA, Solomon-Hill G, Penwell ZR, Powell MD, Wolf MR, Volek JS, Denegar CR, and Maresh CM. Effects of a whole body compression garment on markers of recovery after a heavy resistance workout in men and women. J Strength Cond Res 24: 804-814, 2010 .

21. Kraemer WJ, Gordon SE, Fragala MS, Bush JA, Szivak TK, Flanagan SD, Hooper DR, Looney DP, Triplett NT, DuPont WH, Dziados JE, Marchitelli LJ, and Patton JF. The effects of exercise training programs on plasma concentrations of proenkephalin Peptide $\mathrm{F}$ and catecholamines. Peptides 64: 74-81, 2015.

22. Kraemer WJ, Patton JF, Knuttgen HG, Hannan CJ, Kettler T, Gordon SE, Dziados JE, Fry AC, Frykman PN, and Harman EA. Effects of high-intensity cycle exercise on sympathoadrenal-medullary response patterns. J Appl Physiol (1985) 70: 8-14, 1991.

23. Kraemer WJ, and Ratamess NA. Hormonal responses and adaptations to resistance exercise and training. Sports Med 35: 339-361, 2005.

24. Leatherwood WE, and Dragoo JL. Effect of airline travel on performance: a review of the literature. Br J Sports Med 47: 561-567, 2013.

25. Lemmer B, Kern RI, Nold G, and Lohrer H. Jet lag in athletes after eastward and westward time-zone transition. Chronobiology international 19: 743-764, 2002.

26. Linsell CR, Lightman SL, Mullen PE, Brown MJ, and Causon RC. Circadian rhythms of epinephrine and norepinephrine in man. J Clin Endocrinol Metab 60: 1210-1215, 1985.

27. Miyamoto N, and Kawakami Y. Effect of pressure intensity of compression short-tight on fatigue of thigh muscles. Med Sci Sports Exerc 46: 2168-2174, 2014.

28. Moore AN, Decker AJ, Baarts JN, Dupont AM, Epema JS, Reuther MC, Houser JJ, and Mayhew JL. Effect of competitiveness on forty-yard dash performance in college men and women. J Strength Cond Res 21: 385-388, 2007.

29. Nicholson AN, Pascoe PA, Spencer MB, and Benson AJ. Jet lag and motion sickness. British medical bulletin 49: 285-304, 1993.

30. Reilly T, Atkinson G, and Budgett R. Effect of low-dose temazepam on physiological variables and performance tests following a westerly flight across five time zones. International journal of sports medicine 22: 166-174, 2001.

31. Reiter RJ. Melatonin: the chemical expression of darkness. Mol Cell Endocrinol 79: C153-158, 1991.

32. Reiter RJ. Pineal melatonin: cell biology of its synthesis and of its physiological interactions. Endocr Rev 12: 151-180, 1991. 
75

77

78

79

33. Samuels CH. Jet lag and travel fatigue: a comprehensive management plan for sport medicine physicians and high-performance support teams. Clin J Sport Med 22: 268-273, 2012. 34. Shvartz E, Gaume JG, White RT, and Reibold RC. Hemodynamic responses during prolonged sitting. Journal of applied physiology: respiratory, environmental and exercise physiology 54: 1673-1680, 1983. 35. Sierer SP, Battaglini CL, Mihalik JP, Shields EW, and Tomasini NT. The National Football League Combine: performance differences between drafted and nondrafted players entering the 2004 and 2005 drafts. J Strength Cond Res 22: 6-12, 2008. 36. Smith RS, Guilleminault C, and Efron B. Circadian rhythms and enhanced athletic performance in the National Football League. Sleep 20: 362-365, 1997. 37. Spitzer RL, Terman M, Williams JB, Terman JS, Malt UF, Singer F, and Lewy AJ. Jet lag: clinical features, validation of a new syndrome-specific scale, and lack of response to melatonin in a randomized, double-blind trial. Am J Psychiatry 156: 1392-1396, 1999.

38. Steenland K, and Deddens JA. Effect of travel and rest on performance of professional basketball players. Sleep 20: 366-369, 1997.

39. Szivak TK, Hooper DR, Dunn-Lewis C, Comstock BA, Kupchak BR, Apicella JM, Saenz C, Maresh CM, Denegar CR, and Kraemer WJ. Adrenal cortical responses to highintensity, short rest, resistance exercise in men and women. J Strength Cond Res 27: 748-760, 2013.

40. Trenell MI, Rooney KB, Sue CM, and Thomspon CH. Compression Garments and Recovery from Eccentric Exercise: A (31)P-MRS Study. J Sports Sci Med 5: 106-114, 2006.

41. Van Cauter E, Leproult R, and Kupfer DJ. Effects of gender and age on the levels and circadian rhythmicity of plasma cortisol. J Clin Endocrinol Metab 81: 2468-2473, 1996.

42. Watanuki S, and Murata H. Effects of wearing compression stockings on cardiovascular responses. Ann Physiol Anthropol 13: 121-127, 1994.

43. Waterhouse J, Edwards B, Nevill A, Atkinson G, Reilly T, Davies P, and Godfrey R. Do subjective symptoms predict our perception of jet-lag? Ergonomics 43: 1514-1527, 2000. 44. Waterhouse J, Edwards B, Nevill A, Carvalho S, Atkinson G, Buckley P, Reilly T, Godfrey R, and Ramsay R. Identifying some determinants of "jet lag" and its symptoms: a study of athletes and other travellers. Br J Sports Med 36: 54-60, 2002. 45. Wright JE, Vogel JA, Sampson JB, Knapik JJ, Patton JF, and Daniels WL. Effects of travel across time zones (jet-lag) on exercise capacity and performance. Aviation, space, and environmental medicine 54: 132-137, 1983. 
Table 1. Experimental Design. ' $\mathrm{X}$ ' denotes assessment occurred. All times are in 24 hour clock format. UC $=$ University of Connecticut; $C S U F=C$ alifornia State University Fullerton; FAM = Familiarizations; BL = Baseline; ET = Eastern Time; PT = Pacific Time; CMJ = Countermovement Jump; POMS = Profile of Mood States; PMS = Perceived Muscle Soreness; LJLQ = Liverpool Jet Lag Questionnaire.

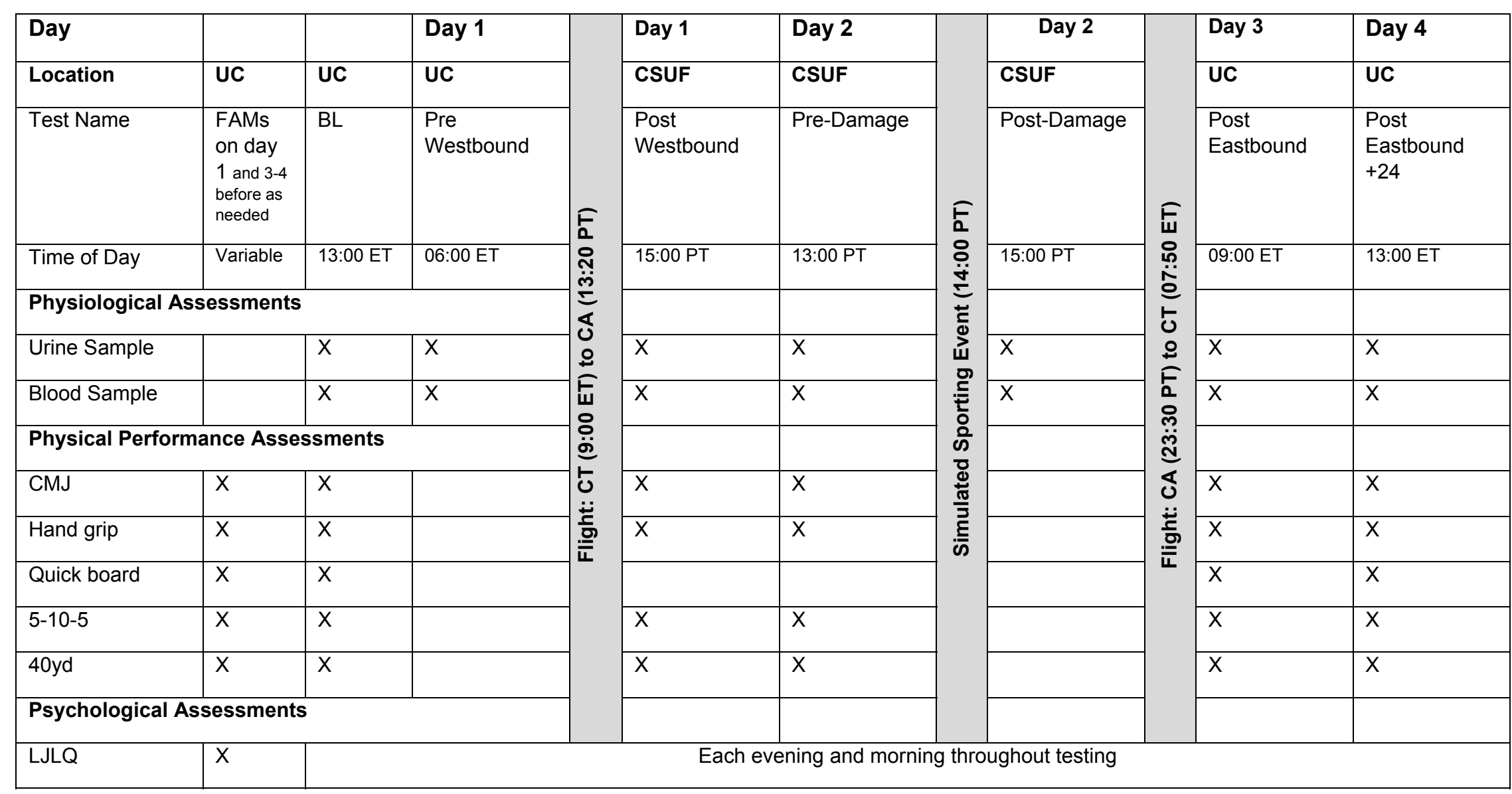


Table 2. Physical Performance Testing. * ${ }^{*}$ Significantly $(\mathrm{P} \leq 0.05)$ different from baseline, $\#=$ significantly $(\mathrm{P} \leq 0.05)$ different from corresponding control condition time point. Post Westbound = immediately following westbound flight; Post Eastbound = immediately following eastbound flight; Post Eastbound $+24=24$ hours following eastbound flight. CMJ = countermovement jump.

\begin{tabular}{|c|c|c|c|c|c|c|}
\hline & \begin{tabular}{l|l} 
& Day: \\
\end{tabular} & 1 & 2 & 3 & 4 & 5 \\
\hline Group & Timepoint: & Baseline & Post Westbound & Pre Exercise & Post Eastbound & $\begin{array}{l}\text { Post Eastbound } \\
+24\end{array}$ \\
\hline \multicolumn{7}{|l|}{ Handgrip (kg) } \\
\hline \multirow[t]{2}{*}{ Control } & Mean: & 51.5 & 48.5 & 49.8 & 47.4 & 48.4 \\
\hline & SD: & 7.5 & 5.2 & 4.8 & 5.0 & 5.9 \\
\hline \multirow[t]{2}{*}{ Compression } & Mean: & 49.0 & 47.7 & 49.8 & 48.1 & 50.6 \\
\hline & SD: & 5.3 & 5.2 & 4.6 & 5.5 & 6.0 \\
\hline \multicolumn{7}{|l|}{$\mathrm{CMJ}(\mathrm{cm})$} \\
\hline \multirow[t]{2}{*}{ Control } & Mean: & 67.4 & $60.3^{\star}$ & $61.7^{*}$ & $57.2^{\star}$ & $60.5^{\star}$ \\
\hline & SD: & 6.9 & 7.6 & 6.3 & 5.6 & 6.4 \\
\hline \multirow[t]{2}{*}{ Compression } & Mean: & 61.9 & 64.0 & 66.3\# & $62.5 \#$ & 63.8\# \\
\hline & SD: & 9.6 & 10.6 & 9.7 & 6.3 & 9.8 \\
\hline \multicolumn{7}{|c|}{ Quickboard (correct touches) } \\
\hline \multirow[t]{2}{*}{ Control } & Mean: & 14.2 & & & $15.9^{\star}$ & 14.8 \\
\hline & SD: & 1.7 & & & 1.4 & 0.8 \\
\hline \multirow[t]{2}{*}{ Compression } & Mean: & 14.9 & & & 14.3\# & 14.7 \\
\hline & SD: & 1.6 & & & 1.0 & 1.2 \\
\hline \multicolumn{7}{|c|}{ Pro Agility Drill (5-10-5) (s) } \\
\hline \multirow[t]{2}{*}{ Control } & Mean: & 4.99 & $5.23^{\star}$ & $5.26^{\star}$ & $5.29 *$ & 5.14 \\
\hline & SD: & 0.38 & 0.49 & 0.37 & 0.32 & 0.35 \\
\hline \multirow[t]{2}{*}{ Compression } & Mean: & 5.01 & $5.03 \#$ & 4.90\# & 4.92\# & 4.91\# \\
\hline & SD: & 0.41 & 0.44 & 0.15 & 0.18 & 0.45 \\
\hline \multicolumn{7}{|l|}{ 40yd Sprint (s) } \\
\hline \multirow[t]{2}{*}{ Control } & Mean: & 5.27 & $5.53^{\star}$ & $5.58 \star$ & $5.65^{\star}$ & 5.36 \\
\hline & SD: & 0.32 & 0.43 & 0.45 & 0.50 & 0.46 \\
\hline \multirow[t]{2}{*}{ Compression } & Mean: & 5.10 & $5.13 \#$ & 5.19\# & $5.17 \#$ & 5.09\# \\
\hline & SD: & 0.20 & 0.27 & 0.23 & 0.25 & 0.24 \\
\hline
\end{tabular}


Table 3. Liverpool Jet Lag Questionnaire (LJLQ) results. * = Significantly $(\mathrm{P} \leq 0.05)$ different from Day 1 PM, \# = significantly $(\mathrm{P} \leq$ 0.05 ) different from corresponding control treatment time point. AM = LJLQ responses in the morning immediately following sleep; $\mathrm{PM}=\mathrm{LJLQ}$ responses in the evening immediately before sleep.

\begin{tabular}{|c|c|c|c|c|c|c|c|c|c|}
\hline \multirow[t]{2}{*}{ Group } & \multirow[t]{2}{*}{ Day: } & \multirow{2}{*}{$\begin{array}{c}\mathbf{1} \\
\text { Pre } \\
\text { Westbound } \\
\end{array}$} & \multicolumn{2}{|c|}{2} & \multicolumn{2}{|c|}{3} & \multicolumn{2}{|c|}{4} & \multirow{2}{*}{$\begin{array}{c}\mathbf{5} \\
\text { Post East } \\
\text { Bound }+24 \\
\end{array}$} \\
\hline & & & $\begin{array}{c}\text { Post } \\
\text { Westbound }\end{array}$ & $\begin{array}{c}\text { Post } \\
\text { Westbound }\end{array}$ & $\begin{array}{c}\text { Post } \\
\text { Westbound }\end{array}$ & $\begin{array}{c}\text { Post } \\
\text { Westbound }\end{array}$ & $\begin{array}{c}\text { Post } \\
\text { Eastbound }\end{array}$ & $\begin{array}{c}\text { Post } \\
\text { Eastbound }\end{array}$ & \\
\hline & Time Point: & PM & AM & PM & AM & PM & AM & PM & AM \\
\hline \multicolumn{10}{|l|}{ Jet Lag (0-10): } \\
\hline \multirow[t]{2}{*}{ Control } & Mean: & 0.07 & 0.10 & $6.45^{\star}$ & $2.14^{\star}$ & $5.40^{\star}$ & $5.64^{\star}$ & $4.30 *$ & 2.81 \\
\hline & SD: & 0.16 & 0.32 & 2.25 & 1.59 & 2.60 & 2.35 & 3.74 & 3.10 \\
\hline \multirow[t]{2}{*}{ Compression } & Mean: & 0.00 & 0.00 & $5.16^{\star}$ & $3.23^{\star}$ & $6.13^{\star}$ & $6.13^{*}$ & $4.64^{\star}$ & $2.03^{*}$ \\
\hline & SD: & 0.00 & 0.00 & 2.72 & 2.83 & 2.30 & 2.30 & 2.87 & 2.44 \\
\hline \multicolumn{10}{|c|}{ Fatigue $(-5-5)$} \\
\hline \multirow[t]{2}{*}{ Control } & Mean: & -0.32 & -0.23 & $-1.92^{\star}$ & 0.51 & $-3.20^{\star}$ & $-3.57^{\star}$ & -0.63 & -1.48 \\
\hline & SD: & 0.67 & 2.41 & 2.67 & 1.82 & 0.79 & 0.93 & 2.58 & 1.78 \\
\hline \multirow[t]{2}{*}{ Compression } & Mean: & -0.47 & -0.75 & $-3.37^{\star}$ & -0.21 & $-3.29^{\star}$ & $-3.82^{*}$ & -1.35 & -0.16 \\
\hline & SD: & 1.22 & 1.55 & 1.22 & 1.50 & 1.99 & 1.47 & 1.00 & 1.14 \\
\hline \multicolumn{10}{|c|}{ Expected Sleep $(-5-5)$ : } \\
\hline \multirow[t]{2}{*}{ Control } & Mean: & 0.14 & & $2.55^{\star}$ & & 0.04 & & 1.25 & \\
\hline & SD: & 0.89 & & 1.96 & & 3.53 & & 1.74 & \\
\hline \multirow[t]{2}{*}{ Compression } & Mean: & -0.75 & & $2.57^{\star}$ & & $-4.22^{*} \#$ & & -0.15 & \\
\hline & SD: & 1.79 & & 1.81 & & 0.47 & & 1.63 & \\
\hline \multicolumn{10}{|c|}{ Actual Sleep $(-5-5)$ : } \\
\hline \multirow[t]{2}{*}{ Control } & Mean: & & 0.64 & & 0.15 & & $-3.50^{\star}$ & & 0.28 \\
\hline & SD: & & 2.11 & & 2.26 & & 2.09 & & 2.74 \\
\hline \multirow[t]{2}{*}{ Compression } & Mean: & & -1.27 & & -0.28 & & $-4.68^{\star}$ & & 0.46 \\
\hline & SD: & & 2.37 & & 2.05 & & 0.37 & & 0.45 \\
\hline
\end{tabular}




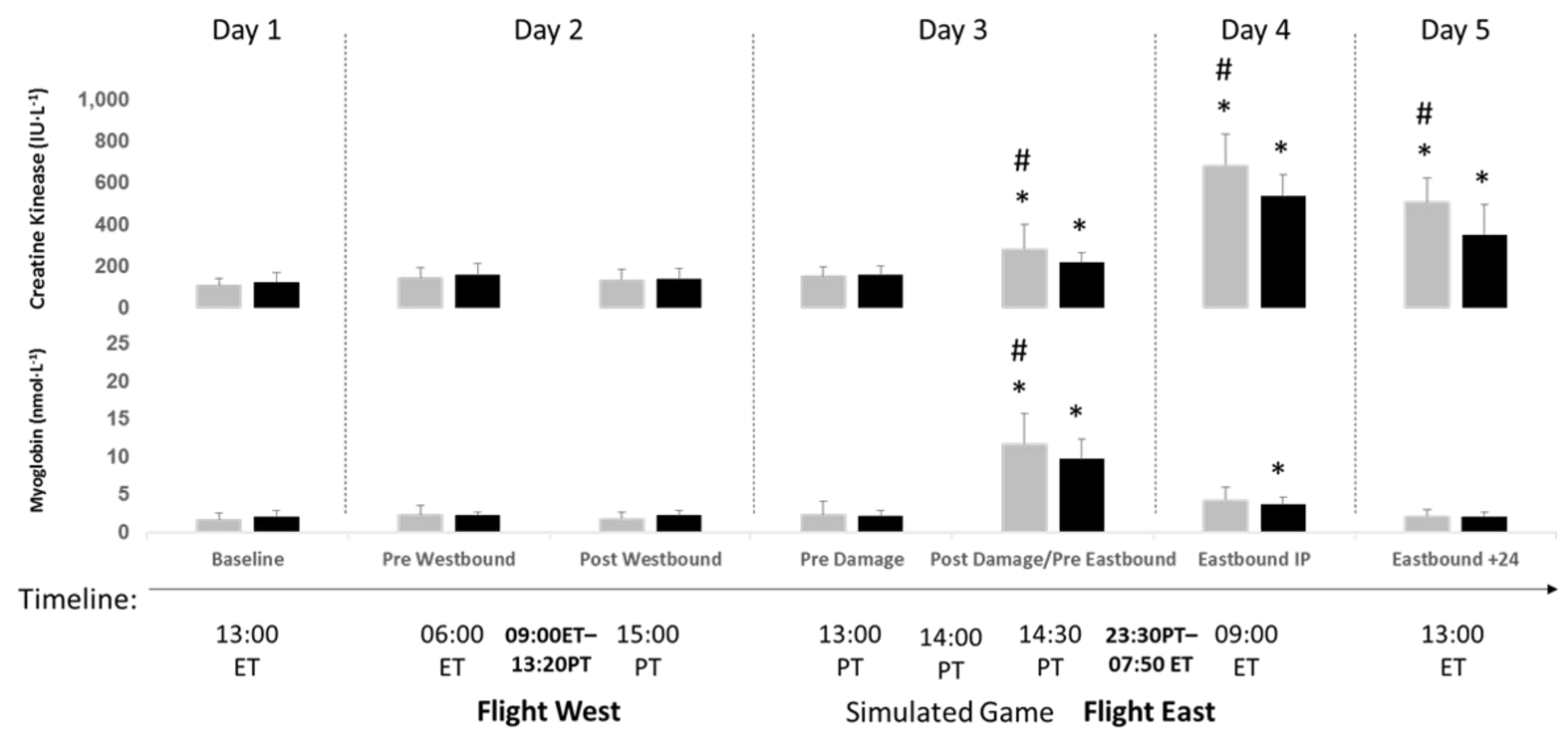




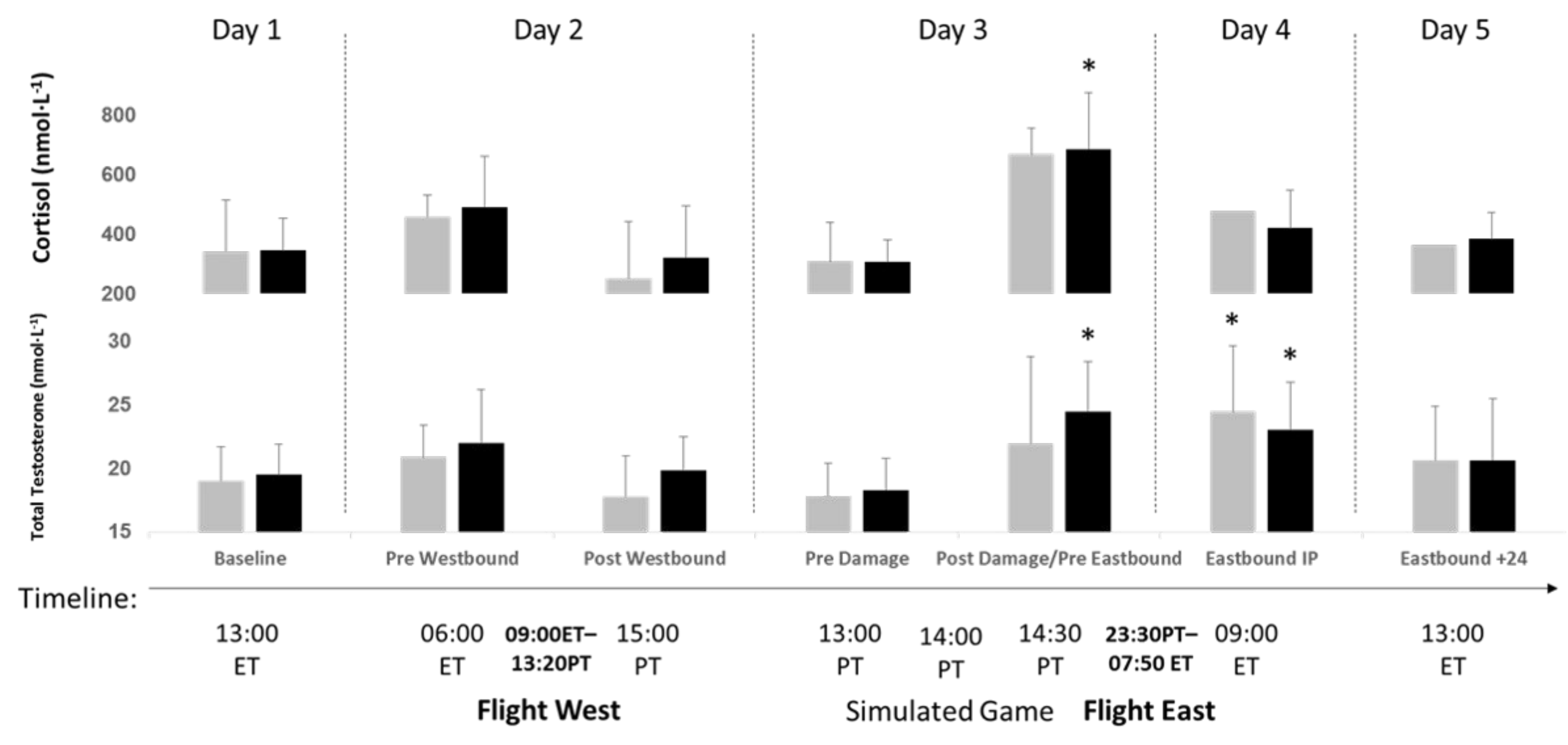

